\title{
ESTRATEGIAS PARA LA INCLUSIÓN DE ESTUDIANTES SORDOS EN LA EDUCACIÓN SUPERIOR LATINOAMERICANA
}

\author{
STRATEGIES FOR THE INCLUSION OF DEAF STUDENTS \\ IN LATIN AMERICAN HIGHER EDUCATION
}

\author{
Miguel Ángel Salazar Durango* \\ Recibido: 20 de agosto de 2017 - Aceptado: 20 de septiembre de 2017 - Publicado 31 julio de 2018 \\ DOI: $10.24142 /$ raju.v13n26a9
}

\section{Resumen}

La universidad, particularmente en Latinoamérica, refleja grandes vacíos en su contexto social. A pesar de los avances académicos e investigativos se suele dejar de lado la riqueza cultural y lingüística de comunidades que hacen parte de la misma realidad social. Un caso puntual es el de la comunidad sorda, cuyo acceso a la educación superior es muy reducido; incluso, quienes ingresan a la universidad pueden enfrentarse a condiciones hostiles y alejadas de una educación humanista. En general, son muy incipientes los procesos que se tienen con la inclusión de esta población en la educación superior. Por eso, en este trabajo se plantean algunas estrategias que pueden adaptarse

Estudiante de Licenciatura en Ciencia Sociales, Universidad Autónoma Latinoamericana (UNAULA). Modelo de Lengua y Cultura para la comunidad sorda en la Institución Educativa Francisco Luis Hernández Betancur. Correo electrónico: miguelangel1514@hotmail.com 
en las instituciones universitarias, con el fin de lograr las transformaciones pertinentes para una educación popular que incluya a estas minorías.

Palabras clave: lengua de señas, minorías lingüísticas, inclusión educativa, comunidad sorda.

\section{Abstract}

The universities, particularly in Latin America, reflect large gaps in its social context. In spite of academic and research advances, the cultural and linguistic richness of communities that are part of the same social reality is often left aside. A specific case is that of the deaf community, whose access to higher education is very limited; even those who enter the university can face hostile conditions and away from a humanistic education. In general, the processes that have the inclusion of this population in higher education are very incipient. For this reason, this article proposes some strategies that can be adapted in the university's institutions, in order to achieve the relevant transformations for a popular education that will include these minorities.

Keywords: sign language, linguistic minorities, educational inclusion, deaf community. 


\section{INTRODUCCIÓN}

En la gran diversidad latente en el género humano existe una condición que tiene implicaciones en la creación de una cultura y lengua distintas: la sordera. Las personas con dificultades para oír, o sordas, al no escuchar, no adquieren la lengua oral de la mayoría de su entorno. En el contexto latinoamericano, el español de las personas sordas es muy deficiente (Ochoa, Gómez y Osorno, 2014). En ese sentido, son una minoría lingüística que tiene una cultura distinta al entorno donde habitan. Así, una verdadera inclusión debe tener en cuenta las particularidades de esta comunidad.

Las personas sordas tienen una lengua propia: la lengua de señas. Esta es ágrafa, visual, gestual y espacial (Liddell, 2005). Con esta lengua se comunican con sus pares y logran expresarse de la misma forma que lo haría un oyente con una lengua oral. La cuestión es que la mayoría no la conoce y, por lo tanto, no son incluidos en gran parte de los espacios que tienen como ciudadanos (Ochoa et al., 2014).

Uno de estos espacios es el de la educación superior, imprescindible para el desarrollo de vida de cualquier persona. En particular, en el caso de las personas en situación de discapacidad, la educación es la puerta más importante para la inclusión social (Echeita y Simón, 2007). Ahora bien, en la interacción maestro-alumno la comunicación es primordial para transmitir los contenidos y garantizar un aprendizaje. Como, en la gran mayoría de los casos, la lengua de ambos (profesor y alumno) es distinta y el acercamiento del sordo al español es tan limitado se requieren ciertas adecuaciones. Incluso, son necesarias adaptaciones desde los demás espacios de interacción, verbi gratia, los compañeros, el acompañamiento estudiantil, eventos fuera de clase a los que desee asistir y demás dimensiones y necesidades propias de un estudiante.

Por lo anterior, se elabora este artículo, el cual pretende realizar una reflexión teórica acerca de las necesidades de inclusión de los sordos en la educación superior latinoamericana, y algunas estrategias académicas y de bienestar que pueden ser adaptadas para garantizar una verdadera inclusión de esta comunidad que, clásicamente, ha sido excluida de tantos espacios, en especial, el de la universidad.

Para tal fin, el artículo se estructura de la siguiente forma: se comienza con algunas definiciones de la investigación cualitativa, la cual se realizó para este proyecto que, si bien es de reflexión teórica, sí presenta algunos resultados de investigación, pero son parciales, ya que la investigación sigue 
en curso; posteriormente, se da una contextualización en varios aspectos de los sordos y su proceso de inclusión en el aula (ingreso del sordo a la educación superior, competencias lingüísticas de los sordos, intérpretes de lengua de señas, desempeño académico de los sordos, factores externos); luego, se detallan algunas estrategias que se han propuesto en el estado del arte para la inclusión de los estudiantes sordos en las universidades; después, son presentados unos casos de estudio de algunos procesos observados como parte del ejercicio de investigación, de estudiantes sordos en ciertas Instituciones de Educación Superior (IES) de la ciudad de Medellín. A continuación, se realiza un análisis de los resultados y, finalmente, se presentan las conclusiones con sus trabajos futuros, los agradecimientos y las referencias bibliográficas.

\section{INVESTIGACIÓN CUALITATIVA}

\section{Aspectos metodológicos de la investigación cualitativa}

La investigación cualitativa busca comprender la conducta humana teniendo como marco de referencia a quien actúa. Además, "contribuye a la teoría, a la práctica educativa, a la elaboración de planes y a la concienciación social" (McMillan y Schumacher, 2005). La investigación cualitativa se enfoca en la descripción y contextualización de la realidad social desde el punto de vista de los investigados.

Por otra parte, sirve para "configurar un concepto acerca del fenómeno [...], encontrar las cualidades que en conjunto caracterizan al fenómeno" (Mella, 1998).

Por lo tanto, la investigación cualitativa es importante porque nos "permite distinguir el fenómeno investigado de otros fenómenos" (Mella, 1998). Se hacen observaciones de un suceso, se obtienen sus cualidades y se consiguen conceptos del fenómeno.

\section{La etnografía como método de investigación social}

La etnografía es "el método de investigación por el que se aprende el modo de vida de una unidad social concreta" (Gómez, Gil y García, 1999, p. 45). Se enfoca en lo microsocial: pequeñas comunidades y se caracteriza por (Abero, Berardi, Capocasale, García y Rojas, 2015): 
- La técnica principal es la observación directa.

- El investigador debe estar un tiempo suficiente en el escenario a estudiar.

- El volumen de información debe ser grande.

- La contextualización del fenómeno es muy importante.

Algunas técnicas sugeridas pueden ser la entrevista no estructurada, la observación participante y las notas o diario de campo.

A veces, pueden servir las experiencias subjetivas del investigador y de los participantes para comprender mejor los fenómenos. Elsie Rockwell (2011) dice que es importante prestar "atención a los significados para lograr interpretarlos durante el proceso continuo de interacción entre el investigador y los sujetos" (p. 86).

El método etnográfico permite "ir más allá de una mera crónica de sucesos particulares, y mirar debajo de ellos con el fin de comprender cómo la gente les hace frente y maximiza o, por el contrario, minimiza la probabilidad de su recurrencia" (Jociles, 1999, p. 9). De manera que la etnografía permite profundizar, tener un mejor conocimiento de los sujetos investigados.

\section{CARACTERÍSTICAS DEL OBJETO DE ESTUDIO: EL SORDO EN LA EDUCACIÓN}

\section{Capacidades cognitivas de las personas sordas}

Desde la antigüedad se creía que las personas sordas tenían menos capacidades intelectuales que los oyentes; incluso hoy, esto es remanente como creencia en algunas personas que sostienen que los sordos no pueden obtener el mismo desarrollo cognitivo que los oyentes. Sin embargo, los hallazgos más importantes de investigaciones neurocientíficas y psicológicas aplicadas a personas sordas, en comparación con personas oyentes durante los últimos cincuenta años, muestran que las personas sordas tienen el mismo nivel de inteligencia que los oyentes (Vernon, 2005).

Así, lo único que los diferencia es que no tienen una lengua oral, sino una lengua ágrafa, aunque visual, que no usa la mayoría. Esto tiene profundas implicaciones en su estructura mental y forma de concebir el mundo, ya que si su lengua es distinta puede desprenderse que su forma de pensar es 
diferente, desde que el lenguaje es la principal mediación entre el hombre y el mundo (Bernal, 2016).

De manera que, si tienen las mismas capacidades cognitivas se podría pensar que su desarrollo académico debería ser similar. Lamentablemente, esto no es así en la mayoría de los casos.

\section{Enfoques para el desarrollo de la persona sorda}

Teniendo en cuenta los aspectos lingüísticos, cognitivos y sociales, existen básicamente dos enfoques para el desarrollo de las personas sordas (Acosta, 2006):

- Enfoque audiológico: se centra en cómo el sordo, con ayudas técnicas como los audífonos o implantes cocleares, más una terapia fonoaudiológica, logra vocalizar emitiendo sonidos al igual que un oyente (emular el habla) y lectura labial para interpretar lo que otra persona está diciendo con solo ver el movimiento y posición de los labios y lengua. Esta perspectiva se enfoca en el déficit, en cómo potenciar la pérdida auditiva.

- Enfoque sociocultural: busca apoyarse sobre la capacidad del sordo, reconociendo y fortaleciendo una lengua y cultura propia que comparte con otros miembros de su comunidad. Esta perspectiva pretende potenciar su identidad y su lengua.

Una propuesta más armónica considera la multidimensionalidad del ser humano (Domínguez y Alonso, 2004), teniendo así una fusión de lo mejor de ambas perspectivas. Se reconoce así que la pérdida auditiva del estudiante sordo tiene como consecuencia la dificultad en el lenguaje oral y escrito, y que este puede trabajarse con ayuda técnica y terapéutica; lo anterior no se contrapone con la formación del sordo en una lengua que es natural a él, que es ágrafa, gestual y visual, la lengua de señas (Belén, 2008).

Muchos casos (véase "Observación y análisis del caso 3") muestran cómo una persona sorda puede tener implante coclear y, a pesar de que algunos la cataloguen como oyente, también puede hacerse partícipe de la identidad y cultura sorda, adquirir la lengua de señas y ser parte de la comunidad (Rodríguez, 2006) 


\section{Modelos educativos para la formación de la persona sorda}

Existen dos aspectos en los que se ha centrado la discusión en el estado del arte que es la modalidad comunicativa que debe usarse en el aula con personas sordas, es decir, la presencia o ausencia de la lengua de señas y el contexto educativo, esto es, si es un centro ordinario integrado con oyentes en diversidad de capacidades o, por el contrario, es un centro especial dedicado a esta discapacidad.

En el ámbito comunicativo se presentan dos paradigmas: el monolingüismo y el bilingüismo. El primero puede darse bajo el enfoque audiológico (mencionado en la sección "Enfoques para el desarrollo de la persona sorda") que procura desarrollar las competencias en la lengua hablante mayoritaria (el español en este caso). Esto se puede lograr a través de estrategias visuales como la logogenia (morfosintáctico-bimodal) o audio-orales, relacionadas con el trabajo fonoaudiológio (fonológico-palabra complementada) (Guerrero, 2015). Por el contrario, es posible hallarla en escenarios pedagógicos donde se use exclusivamente la lengua de señas, sin considerar la lengua que prima en el contexto sociocultural del alumno sordo.

El modelo educativo bajo el bilingüismo en sordos contempla el uso de ambas lenguas, la de señas, como su lengua nativa, y la oral circundante, como su segunda lengua. Este modelo propone los siguientes elementos (Belén, 2008):

- En las primeras edades la lengua de señas es la herramienta de interacción comunicativa; posteriormente, se convierte en la lengua de enseñanza.

- Establecer la lengua de señas dentro de un área curricular.

- Incorporación de esquemas de trabajo en el bilingüismo.

- Inclusión de adultos sordos que pueden mediar en el proceso educativo como tutores y modelos de lengua de señas y cultura sorda.

Por otra parte, frente a los enfoques de la integración completa (sordos y oyentes en la misma clase) y de la especialización completa (solo con sordos) existen múltiples posturas. Cada uno tiene sus ventajas y desventajas. Sin embargo, es posible armonizar estos paradigmas educativos. En ese sentido, debe entenderse que 
la inclusión no es solamente un lugar sino, en esencia, una actitud y un valor de profundo respeto por las diferencias y de compromiso con la tarea de no hacer de ellas obstáculos sino oportunidades (Ainscow, 2008; Echeita, 2006; Powers, 1996) (...). La cuestión no está en discutir si es más indicado que estos alumnos se escolaricen en centros de integración o en centros especiales, sino, más bien, sobre cuáles son las características que debe tener un determinado centro, sea este ordinario o específico, para responder adecuadamente al reto educativo que plantean estos alumnos, extrayendo las ventajas de cada uno de los contextos (Belén, 2008, p. 50).

\section{Situación de las personas sordas en la educación superior}

La experiencia que han tenido las comunidades sordas en Latinoamérica ha estado caracterizada por la

exclusión, frustración, currículos abreviados, bajas expectativas académicas, ingresos tardíos a la escolaridad y al acceso a su lengua natural [la lengua de señas] y desde políticas educativas trazadas en ausencia de estas comunidades, desconociendo sus historias, su ciudadanía, su trabajo, su lengua, sus construcciones identitarias (Ramírez y Rendón, 2013, p. 194).

y sus capacidades.

Para acceder a la educación superior están las IES públicas y privadas. Dadas las precarias condiciones económicas de la mayoría de los sordos (Ministerio de Salud y Protección Social, 2012), la mejor posibilidad sería una universidad pública, pero sus exámenes de admisión, a pesar de las adaptaciones que se han hecho, preservan una orientación hacia la evaluación de personas oyentes, lo cual restringe el acceso a la universidad por parte de los sordos. Las preguntas de los exámenes de admisión suelen enmarcarse en el español, que es una segunda lengua para los sordos y que los pone en desigualdad de condiciones (Ramírez y Rendón, 2013). Incluso, aunque aplicaran a becas, la mayoría exigen altos puntajes en las pruebas de Estado que, al igual que en los exámenes, son orientadas a oyentes y exigen conocimientos idiomáticos que no están al alcance del sordo: metáforas, hipérboles, parábolas y demás figuras literarias que se usan de una forma muy distinta en la lengua de señas. 


\section{PRESENTACIÓN Y ANÁLISIS DE CASOS DE ESTUDIO}

Se realizó un trabajo de campo analizando cuatro sujetos de la situación problema. A través de una investigación cualitativa, aplicando el método etnográfico, se elaboró un diario de campo y entrevistas semiestructuradas. A continuación, se presentan los resultados de la investigación realizada, y que sigue su curso, junto a un análisis de los mismos.

\section{OBSERVACIÓN Y ANÁLISIS DEL CASO 1}

Daniel $^{1}$ es una persona sorda de nacimiento. Cuando tenía cuatro años sus padres lo ingresaron en una institución educativa enfocada en la oralización. Allí le enseñaban a leer los labios y a vocalizar, para tratar de emular algunos sonidos como si hablara. Estuvo en esta entidad dos años, pero sus padres vieron que se estancó. No logró despegar en habilidades de oralización. Buscaron otra institución y encontraron que había una especializada en estudiantes sordos, pero bajo un enfoque de la sordera desde su lengua natural: la lengua de señas. Una vez ingresó su adaptación fue fácil.

Él mismo narra cómo recuerda que al llegar a la institución y ver las señas quedó impactado. Le resultaba impresionante ver que se podía comunicar con otras personas de una manera fluida, sin usar la voz ni el esfuerzo que le costaba la oralización. Así, su vida en el colegio fue estable y provechosa. Se graduó con honores, siendo el mejor de su clase en las pruebas de Estado.

Luego buscó en universidades de la ciudad donde pudiera estudiar Derecho. La situación económica de su familia le permitió aplicar a una universidad privada. El examen de admisión consistió en una entrevista. Allí estuvo acompañado por el intérprete. La situación problemática se dio cuando la universidad lo aceptó y dijo que le pondría intérprete para las clases, pero no lo hizo.

En estos casos, la estrategia de adecuación en el aula es clara: se debe contar con un intérprete de lengua de señas. La universidad hizo caso omiso a este derecho que contempla la legislación colombiana y el estudiante radicó entonces una tutela. El juez falló a favor de Daniel y la universidad, cumpliendo con su deber, acató la norma.

1 Se modifican los nombres propios por respeto a la intimidad de la persona y buen nombre de las instituciones. 
Ahora, traer esta situación a la investigación denota no solo un proceso que puede ser representativo de la comunidad, sino el desconocimiento que tienen las instituciones acerca de las acciones requeridas para la inclusión. En este caso puntual, también se resalta la falta de voluntad para adecuar de forma pertinente los espacios educativos para los estudiantes sordos.

Adicional a la situación mencionada surge otro problema. Ya se cuenta con el intérprete para las clases, empero, no se contempla para el acompañamiento durante las lecturas. En principio, se pensaría que es responsabilidad del estudiante abordar las tareas y trabajos asignados en las clases. Es cierto. Sin embargo, considerando las dificultades que tienen las personas sordas para la lectura y escritura del español, esta labor es bastante compleja, en especial si se tiene en cuenta que se maneja un discurso académico. En ese sentido, la sugerencia es que el intérprete también lo acompañe en las lecturas.

Un contraargumento sostiene la importancia de crear independencia en el sordo para evitar la permanente necesidad de un intérprete en el entendimiento de un texto académico. Son posturas válidas, que se pueden enfocar en una propuesta donde el intérprete pueda no solo traducir las lecturas, sino explicar su contenido y algunos elementos gramaticales del español. Ahora, un intérprete no necesariamente está facultado para esta labor, de manera que el escenario ideal sería que contara con clases para la mejora del español como segunda lengua.

Por otra parte, se detecta un vacío léxico y, por lo tanto, conceptual en este estudiante. Con base en el método etnográfico se puede realizar un análisis inductivo para establecer que es común en la comunidad sorda. La tesis se basa en que la lengua la construyen los usuarios de la misma. En este caso, los sordos clásicamente no han accedido a la universidad y, como consecuencia, las señas oficiales existentes son limitadas.

El argot manejado en ámbitos más especializados no es cubierto por la lengua de señas colombiana existente a la fecha. "En la actualidad, la lengua de señas colombiana encara procesos de estandarización derivados del reciente interés de la comunidad Sorda y las autoridades por generar políticas linguísticas que respondan al uso de la lengua en contextos académicos y formales" (Barreto y Cortés, 2014, pp. 247-248). En otras palabras, apenas se está construyendo el déficit léxico de la lengua de señas académicas. Y esto implica que muchos conceptos vistos en un discurso, dentro de un espacio pedagógico, no tengan una seña asociada (Tovar, 2010). En ese sentido, lo que ocurre es que primero se explica el concepto y luego, en un acuerdo 
entre el estudiante y el intérprete, se designa una seña; siendo no oficial, y quedando tan solo como un acuerdo entre ellos.

A pesar de las propuestas anteriores, esta universidad no le ofrece estos servicios a Daniel. Con dificultad, la universidad le garantiza el intérprete durante las clases. Es el derecho del estudiante, y lo hizo defender con la protección jurídica de la legislación colombiana. Pero para acompañamientos adicionales la institución sostiene que se sale del presupuesto. Independientemente de la situación, no contar con esta atención, de alguna manera, puede ser la causa por la que continuamente fracasa en las asignaturas. Daniel, para poder realizar los trabajos y lecturas suele recurrir a fundaciones o amigos que, de forma voluntaria o por un valor asequible puedan ayudarle en esta labor.

Finalmente, aunque Daniel fue un estudiante destacado en su colegio (para personas sordas) en la universidad se dio cuenta de los vacíos conceptuales que tenía y de la importancia de conseguir mayores fortalezas en el español, a pesar de haber estado asistiendo durante tres años a talleres de logogenia para la mejora del idioma.

\section{OBSERVACIÓN Y ANÁLISIS DEL CASO 2}

David es una persona sorda que tiene el anhelo de estudiar Ciencias Políticas. Por sus dificultades económicas no se le ha facilitado encontrar una universidad privada. Y su bajo desempeño en las pruebas de Estado no le permiten acceder fácilmente a una beca. Ha aplicado a las universidades públicas, pero nunca ha sido aceptado. Las universidades han realizado ciertas adecuaciones a los exámenes para que cuenten con el servicio de intérprete. Sin embargo, no es suficiente.

David manifiesta que ese es el sentir de muchos: que la mayoría de las instituciones educativas no han entendido las necesidades de la comunidad sorda y, por ende, han sido excluidos de la educación superior. El problema está en el enfoque: se ven a los sordos como deficientes auditivos y no como una minoría lingüística con competencias y saberes particulares (Ramírez y Rendón, 2013).

Actualmente, se ha trabajado en adaptar los exámenes para que sean realmente justos y equitativos, que sean exigentes y del mismo nivel pero teniendo en cuenta las particularidades del estudiante. 


\section{OBSERVACIÓN Y ANÁLISIS DEL CASO 3}

Susana perdió la audición a los dos años por causa de una meningitis bacteriana aguda. Su niñez y adolescencia la pasó en un colegio con personas oyentes. Fue a terapias con fonoaudiólogos para leer los labios y vocalizar. A los seis años, después de ganar una tutela, le pusieron implante coclear. Todo esto le ha ayudado a que su comunicación con oyentes sea más fluida y no requiera siempre usar las señas.

Finalizado el colegio, aplicó a una universidad pública. En el segundo intento logró ingresar a la carrera seleccionada: Zootecnia. El primer semestre trató de estudiar sin intérprete. Seguir su técnica de leer labios. Sin embargo, se sintió frustrada ya que los docentes a veces hablan mientras escriben en el tablero sin mirar a los estudiantes, además de utilizar un lenguaje técnico especializado desconocido por Susana. Por esto, pidió un intérprete en el segundo semestre y la universidad se lo consiguió.

En el segundo semestre no logró adaptarse bien con el intérprete de lengua de señas, ya que además de la poca empatía el intérprete se sostenía en la postura de exigirle a la estudiante usar las señas que él sabía. Es decir, no se adaptó al sordo, sino que le exigió al sordo adaptarse a su forma de signar. Así que pidió un cambio de intérprete para el siguiente semestre. Con este último sigue a la fecha y ha mostrado un excelente desempeño.

Un buen intérprete es parte de las estrategias. No basta con que sea una persona que sepa señas. Debe ser un intérprete de lengua de señas capacitado y que respete los principios deontológicos de su labor.

\section{OBSERVACIÓN Y ANÁLISIS DEL CASO 4}

Cuando David se graduó del colegio quiso estudiar Licenciatura en Español. Encontró una oportunidad en una institución de educación superior en modalidad virtual. Sin embargo, a pesar de que la universidad contaba con intérprete de lengua de señas la manera en que se aplicó la modalidad virtual no fue satisfactoria para David.

La poca interacción con los compañeros, el no poder estar cara a cara con el docente ni el intérprete, las lecturas sin un acompañamiento, fueron factores que contribuyeron a que David desistiera de continuar en su formación en esta licenciatura. Esto no quiere decir que la educación virtual sea necesariamente mala. Este es un caso particular. Algunos estu- 
dios muestran buenos resultados en la educación virtual incluyente (Fuertes, González, Mariscal y Ruiz, 2005).

A pesar de que este sordo se saliera de la universidad no desistió en sus sueños y buscó oportunidades en otra entidad. En la segunda universidad estudió Licenciatura en Ciencias Sociales, siendo el primer estudiante sordo en ella. Esta institución se ha mostrado muy receptiva para las adecuaciones necesarias. A continuación, se listan algunas estrategias que han mostrado efectividad en este proceso:

- La universidad no se retrasa en la contratación del intérprete cada semestre. Lamentablemente, es habitual, por lo menos en lo constatado desde la observación directa para la ciudad de Medellín, que la contratación de los intérpretes de lengua de señas se retrase. Esto afecta mucho el proceso académico, ya que hay un vacío de las lecciones iniciales que suelen servir para la contextualización de las asignaturas. En el peor de los escenarios, el estudiante se ve obligado a radicar una tutela. En este caso, no ha sido así. Siempre procuran estar en regla para el inicio de clases.

- En los primeros meses de haber ingresado el estudiante se le abrió un espacio para sensibilizar a la comunidad universitaria. Estos espacios son importantes, ya que la universidad no son solo las clases. Es un lugar para compartir con todos los integrantes, para desarrollarse de forma integral. El saber es una construcción social cotidiana, por lo que cada encuentro, cada rincón es un espacio de interacción y aprendizaje. En este sentido, los demás miembros de la comunidad universitaria han de ser conscientes de la presencia y necesidades de las personas sordas.

- En el aula de clase los trabajos escritos son habituales. David proponía, en muchas ocasiones, que pudiera cambiar lo escrito por una exposición o video. Esto debido a que la lengua de señas es su lengua nativa y el español su segunda lengua. Los profesores aceptan, naturalmente, previo acuerdo con el estudiante.

- $\mathrm{Al}$ estar becado el estudiante debe contribuir con horas de trabajo social. El estudiante propuso que esta labor la podría dedicar a dar cursos de lengua de señas gratuitas para todos los miembros de la comunidad universitaria. Esto es un gana-gana. Los miembros de la universidad se van a tener que enfrentar a personas sordas en algún momento, si ya tienen algún conocimiento, así sea básico, 
pueden ser más efectivos en su relación con el sordo. Por parte de David, esto también sería un beneficio, ya que podría interactuar con más personas al interior de la universidad.

\section{OBSERVACIÓN Y ANÁLISIS DEL CASO 5}

Manuel y Javier estudian Ingeniería de Sistemas en otra institución de la ciudad de Medellín. Allí el proyecto de bienestar y acompañamiento universitario cuenta con un equipo enfocado en la población sorda. La comunidad sorda ha visto en esta institución una oportunidad de estudiar, si bien no todas las carreras que desearían, hay por lo menos un abanico de posibilidades del que pueden escoger.

Una ventaja es que no están solos. Allí hay un grupo de por lo menos quince estudiantes sordos. Esto es importante porque cuando son más sordos se pueden apoyar más fácil, explicar entre ellos, hacer trabajos juntos, acordar señas para los conceptos, etc. La institución ha querido incluir a esta población brindándoles herramientas como la logogenia y logodáctica para el aprendizaje del español (Olsen, 2016). Además, de un guía de apoyo para resolver las dudas de forma personalizada y un sistema de tutores a los que pueden acudir para aclarar inquietudes.

En este proceso continúan y, en general, se han tenido buenos resultados. Manuel presentó la tesis y está próximo a graduarse. Javier está en la mitad de la carrera pero ha mostrado avances.

\section{ANÁLISIS DE RESULTADOS Y PROPUESTAS DE APLICACIÓN}

Son múltiples los casos que se pueden analizar y citar aquí, pero es una la realidad: faltan oportunidades y adecuaciones en las IES para el ingreso, permanencia y graduación con calidad de la población sorda.

De los casos observados se concluye que, por una parte, hace falta conocimiento, sensibilización y voluntad en varias IES acerca de las adaptaciones necesarias para la inclusión del estudiante sordo.

Por otro lado, los estudiantes sordos tienen grandes dificultades para el español y, teniendo en cuenta que en el ámbito universitario la lectura es primordial, es menester la adición de horas de acompañamiento por parte del intérprete para las lecturas, y de algunos espacios donde pueda mejorar sus destrezas en el español. Cuando esto ocurre, se han visto mejores resul- 
tados. Hay un mejor desempeño académico si hay herramientas pedagógicas pertinentes para una fructífera vivencia en la educación superior.

Se debe tener en cuenta que, si bien el servicio de interpretación es imprescindible no es garantía de éxito (Caicedo, Castellanos y Muete, 2008). Es una condición necesaria mas no suficiente. El sordo debe aprender a desempeñarse con independencia y siendo más autodidacta en muchos casos.

\section{ESTRATEGIAS PARA LA INCLUSIÓN DEL SORDO EN LA EDUCACIÓN SUPERIOR}

\section{Acceso a la educación}

Como se mencionó en la sección "Enfoques para el desarrollo de la persona sorda" y se mostró con el caso 2, el ingreso a la universidad es una de las primeras barreras que deben romperse. Lo primero sería realizar un cambio estructural de los exámenes, tanto del de Estado como los de ingreso a las universidades. Estos están enfocados en la lengua oral, es decir, hacia las competencias de la lengua castellana. Es cierto que no se debería eximir a los sordos de un conocimiento del español, pero obligarlos a que se evalúen sus capacidades y saberes por una lengua que no es su lengua nativa sería contraproducente, además de discriminatorio.

Ahora bien, en cualquier caso, sería ideal catalogar a esta comunidad como estudiantes especiales, de forma que el puntaje de acceso exigido esté más acorde a sus condiciones de minoría lingüística. Son una población con una lengua propia que "conlleva la construcción de una impronta cultural identitaria inherente a su lengua" (Ramírez y Rendón, 2013, s. p.). Actualmente, se consideran como población discapacitada, que en parte es cierto, pero no si se reconoce que realmente su discapacidad es no dominar la lengua mayoritaria, teniendo, como minoría, una lengua nativa. Podría pensarse que la anterior propuesta sería efectiva si se aplicase tanto para el ingreso a las universidades públicas como para el acceso a becas para estudio de las personas sordas.

\section{Intérpretes de lengua de señas}

Una vez el sordo haya accedido deben hacerse otras adecuaciones. La principal es tener un intérprete de lengua de señas en las clases y demás espacios que lo requieran. 
Una problemática frecuentemente observada es la existencia de algunos intérpretes que carecen de las competencias lingüísticas suficientes, o del profesionalismo requerido para un contexto académico como el universitario.

En los espacios académicos de la educación superior suele darse una dinámica donde se encuentra: un docente con un discurso especializado y enfocado en los contenidos de su materia, un intérprete que traduce este mensaje a lengua de señas y el estudiante sordo. Tanto el emisor como el receptor del mensaje deben estar en sintonía. Sin embargo, en ocasiones, el intérprete distorsiona el mensaje por falta de profesionalidad.

Dentro de los efectos vistos en este escenario se encuentran los grandes vacíos conceptuales con los que quedan algunos estudiantes sordos, y lo que es peor, en ocasiones son promovidos y graduados teniendo estas falencias. En esta instancia, partiendo de las posturas de autores como Piaget, Vygotsky y Sartori, se establece una relación entre el pensamiento y el lenguaje, hasta el punto de que uno afecta al otro. De manera que el hecho de que un intérprete de lengua de señas distorsione el proceso comunicativo por su falta de profesionalismo trae como consecuencia directa una barrera en el desarrollo del pensamiento del estudiante.

Naturalmente, las deficiencias interpretativas pueden repercutir en el bajo desempeño académico, lo que lleva a una posible deserción y la frustración de no entender los contenidos de las asignaturas.

Ahora bien, qué características debe tener el intérprete para que pueda realizar bien su labor. Aquí se destacan algunas investigaciones al respecto (Dean \& Pollard, 2001; Bao y Montesino, 2011). En ellas se plantean varios aspectos que se deben considerar para la interpretación en lengua de señas: el lingüístico, el ambiental, el interpersonal y el intrapesonal; lo cual implica el desarrollo de ciertas destrezas como la gestualidad, la empatía, la terminología, la fluidez, la cohesión lógica, entre otros.

Como solución a esta problemática se propone lo siguiente (Salazar, 2016):

- Revisión de los manuales de ética para la interpretación en lengua de señas.

- El intérprete debería ser profesional en áreas afines a la carrera del estudiante, o por lo menos, estudiar los conceptos de las asignaturas respectivas. 
- Propiciar espacios de estudio por fuera de clase, con compañía del intérprete, para afianzar los conocimientos y práctica de lectoescritura.

- Espacio para la elaboración de señas académicas.

- Grupos de estudio de sordos para compartir experiencias y saberes.

- Grupos de formación de intérpretes para fortalecer competencias comunicativas.

\section{Bilingüismo y biculturalidad}

Teniendo un visión funcionalista y comunicativa, la lengua, más allá de la concatenación de palabras, es un instrumento de construcción cultural, ya que media los procesos de interacción y diálogo con otras personas (Graham, 2008). Así, la apertura de espacios donde puedan hablarse ambas lenguas, ambas culturas (la sorda y la oyente), permitirá la convergencia hacia la inclusión social. Se construye una sociedad diversa que se apoya en este diálogo intercultural.

Por lo anterior, se hace necesario que, de ambas partes, existan esfuerzos para acercar estos discursos. Es decir, que los oyentes aprendan un poco de lengua de señas y elementos de la cultura e identidad sorda y, por su parte, que los sordos aprendan español y de la convivencia en un mundo de oyentes. Por mucho que se quiera respetar la identidad sorda y su lengua nativa siempre será menester que el sordo maneje competencias lingüísticas básicas para la comunicación con el oyente, ya que vive en una sociedad alfabetizada que usa una lengua oral y escrita (Cáceres, 2013). Así, es ideal que la universidad abra espacios para que los oyentes puedan aprender lengua de señas (puede ser un servicio social gratuito del sordo en contraprestación por los beneficios a los que ha accedido) y que los sordos puedan tener un espacio para mejorar el español, ya sea a través de la lectura y estudio con un intérprete capacitado o con un logogenista especializado en acompañamiento universitario. 


\section{Adaptaciones curriculares}

En principio, debe respetarse el currículo y seguirse como está establecido. Solo hacer adecuaciones cuando realmente se justifiquen. Por ejemplo, en las asignaturas relacionadas con lo musical deben explorarse estrategias para abordarlas desde una perspectiva diferente, o bien, suplirlas por otras en la que el sordo pueda profundizar distintos aspectos. Otro ejemplo es el de una tercera lengua cuando el requisito pueda indicar que se exigen dos lenguas para graduarse. Si este es el caso, se puede plantear al estudiante que fortalezca sus competencias en el español como segunda lengua, y la tercera lengua (generalmente el inglés) pueda estudiarse mas no necesariamente evaluarse.

Ahora bien, dentro de las asignaturas sí es importante que el docente adecúe sus estrategias didácticas para poder llegar al estudiante sordo. Por ejemplo, es mucho más efectiva una clase con gráficos, mapas mentales, mapas conceptuales, dibujos, esquemas en general, diapositivas, videos, representaciones, actividades lúdicas, etc., que una clase donde el docente solo transmite un mensaje en forma de monólogo, citando autores sin dar contexto o una esquematización que permita un efectivo aprendizaje.

Se deben buscar estrategias didácticas que respondan a las motivaciones e intereses de los estudiantes, considerando sus diversas capacidades de aprendizaje y estilos de pensamiento (Belén, 2008).

Las adaptaciones curriculares incluyen tener en cuenta las condiciones del sordo, por ejemplo, a la hora de la evaluación. Así, un examen escrito, considerando que interpretar en lengua de señas puede tomar más tiempo, debería extenderse un tiempo prudencial acordado previamente, con el fin de que pueda ser evaluado con condiciones equitativas. De igual modo, puede plantearse, cuando se requiera hacer un trabajo escrito, que se realice en lengua de señas a través de un video, o una exposición al grupo con los mismos objetivos que el trabajo asignado a los oyentes.

\section{Creación de redes de apoyo}

Tanto los estudiantes como los docentes pueden establecer puntos de encuentro donde retroalimenten las fortalezas y debilidades de sus procesos, de manera que se pueda trabajar hacia una mejora continua. Así, servirán todas las experiencias para no cometer los mismos errores. Esta red puede 
ser interna o abrirse a la comunidad universitaria regional, según el deseo de los docentes.

En el caso de los sordos, la ayuda mutua entre estudiantes universitarios es un proyecto de mucho valor, ya que los acuerdos de señas, la explicación de conceptos, el uso de neologismos y de técnicas de estudio son herramientas que sirven para que el estudiante sordo no desista de sus estudios.

\section{CONCLUSIONES}

Las IES deben realizar ajustes para que las personas sordas sean realmente incluidas como minoría lingüística. Se debe pasar de un enfoque donde se les ve como discapacitados a una visión donde se valore el potencial que tienen escondido detrás de una lengua que es ágrafa, pero con una gran riqueza lingüística que manifiesta su visión del mundo, su identidad y cultura.

Se logró investigar, de forma cualitativa, la situación problema centrándola en la ciudad de Medellín, a través de una investigación etnográfica en la que se partió por observar y entrevistar a cinco personas sordas que están en alguna universidad o aspiran a entrar en ella. Se analizaron las situaciones de estas personas para luego contrastarlas con estudios presentados en el estado del arte.

Se realizan propuestas de estrategias para la inclusión de estudiantes sordos: adecuar las formas de acceso a la educación superior por parte de la comunidad sorda, reconociéndoles sus competencias lingüísticas a través de una evaluación que los mida en su lengua nativa; acompañamiento por parte de un intérprete de lengua de señas adecuado (se presentan algunos parámetros para medir este nivel de calidad); el bilingüismo como enfoque que permita la mejora en habilidades comunicativas del sordo y el biculturalismo, que facilite la inclusión como forma de interactuar entre el mundo sordo y el oyente; adaptaciones curriculares necesarias para la equiparación de oportunidades, construcción de redes de apoyo para recolectar experiencias que sirvan de retroalimentación para la mejora continua.

Como trabajo futuro queda continuar con la investigación en curso y validar si la aplicación de las propuestas es fructífera y suficiente. 


\section{REFERENCIAS}

Abero, L., Berardi, L., Capocasale, A., García M., y Rojas S. (2015). Investigación educativa. Abriendo puertas al conocimiento. Montevideo: Contexto.

Acosta, V. M. (2006). Perspectivas en el estudio de la sordera. En La sordera desde la diversidad cultural y lingüística: construyendo centros inclusivos en la educación del alumnado con sordera (pp. 1-26). Barcelona: Masson.

Ainscow, M. (2008). Understanding the Development of Inclusive Schools. Londres: Falmer Press.

Barreto, A., y Cortés, Y. (2014). Aspectos relevantes del discurso en Lengua de Señas Colombiana. En Panorama de los estudios del discurso en Colombia (pp. 245-281). Bogotá: Universidad Distrital Francisco José de Caldas.

Bao, M. C., y Montesino, R. H. G (2011). Aproximación a los parámetros de calidad en la interpretación de la lengua de signos española. En R. Barranco-Droege, E. M. Pradas y O. García (Eds.), Quality in Interpreting: Widening the Acope (pp. 293-314). Granada: Comares.

Belén, A. (2008). Educación para la inclusión de alumnos sordos. Revista Latinoamericana de Educación Inclusiva, 3(1), 45-61. Recuperado de http://www.rinace.net/rlei/numeros/vol3-num1/art4.pdf

Bernal, S. (2016). Del lenguaje hacia la pedagogía de la lengua en la formación del sujeto social. Enunciación, 21(1), 11-13.

Cáceres, R. G. (2013). Actitudes hacia la escritura en alumnos sordos y oyentes integrados en contextos escolares bilingües. Profesorado, 17(1), 385-400.

Caicedo, D., Castellanos, S., y Muete, M. (2008). Adaptaciones pedagógicas para estudiantes sordos en la Universidad Nacional de Colombia. Revista Colombiana de Educación, (54), 120-141. Recuperado de http:// www.redalyc.org/articulo.oa?id=413635248007

Dean, R. K. \& Pollard, R. Q. (2001). Application of Demand-Control Theory to Sign Language Interpreting: Implications for Stress and Interpreter Training. Journal of Deaf Studies and Deaf Education, 6(1), 1-14.

Domínguez, A. B., y Alonso, P. (2004). La educación de los alumnos sordos hoy: perspectivas y respuestas educativas. Málaga: Archidona.

Echeita, G., y Simón, C. (2007). La contribución de la educación escolar a la calidad de vida de las personas con discapacidad. Ante el desafío 
de su inclusión social. Recuperado de http://educacion.gob.ec/wp-content/ uploads/downloads/2014/07/Tratado-sobre-discapacidad.pdf

Echeita, G. (2006). Educación para la inclusión o educación sin exclusiones. Madrid: Nancea.

Fuertes, J. L., González, Á. L., Mariscal, G., y Ruiz, C. (2005). Herramientas de apoyo a la educación de personas sordas en la universidad española. Métodos Pedagógicos Innovadores, XI Jornadas de Enseñanza Universitaria de La Informática, 430(45), 45-52.

Gómez, G., Gil, J., y García, E. (1999). Metodología de la investigación cualitativa. Granada: Aljibe.

Graham, S. (2008). Research on Writing Development, Practice, Instruction and Assessment. Reading and Writing, 21(1), 1-2.

Guerrero, R. C. (2015). Atención temprana en niños con deficiencia auditiva: herramientas y pautas para una inclusión educativa [tesis de grado, Educación Infantil]. Universidad de Navarra, Pamplona, España.

Jociles, M. I. (1999). Las técnicas de investigación en antropología. Mirada antropológica y proceso etnográfico. Gazeta de Antropología, 15(1), $1-26$.

Liddell, S. (2005). Grammar, Gesture, and Meaning in American Sign Language (Review). Sign Language Studies, Cambridge University Press, 5(4), 506-523.

McMillan, J. S., y Schumacher, S. (2005). Investigación educativa: una introducción conceptual. Madrid: Pearson.

Mella, O. (1998). Naturaleza y orientaciones teórico-metodológicas de la investigación cualitativa. Santiago de Chile: CIDE.

Ministerio de Salud y Protección Social (2012). Registro de localización y caracterización de personas con discapacidad. Bogotá: DANE.

Ochoa, L., Gómez, A. C., y Osorno, M. L. (2014). Evaluación de un programa de acompañamiento en los procesos de lectura y escritura a estudiantes sordos. Entornos, 26(2), 171-179.

Olsen, M. (2016). Proyecto de intervención para el desarrollo de la competencia lingüística del alumnado con discapacidad auditiva a través de la logogenia. Universidad de Granada [s. d.].

Powers, S. (1996). Inclusion is an Attitude not a Place: Part I. Journal of the British Association of the Teachers of the Deaf, 20(2), 35-41.

Ramírez, M., y Rendón, L. (2013). Exclusiones lingüísticas y culturales de las comunidades sordas para el ingreso a la Educación Superior. En Discapacidad en Latinoamérica: voces y experiencias universitarias (pp. 193-199). Buenos Aires: Editorial de la Universidad Nacional de La Plata. 
Rockwell, E. (2011). La experiencia etnográfica. Historia y cultura en los procesos educativos. Buenos Aires: Paidós.

Rodríguez, P. (2006). El bilingüismo en la educación de los alumnos sordos. En La sordera desde la diversidad lingüística y cultural. Construyendo escuelas inclusivas en la educación de las personas sordas (pp. 115124). Barcelona: Masson.

Salazar, M. Á. (2016). Problemas de la interpretación en la educación superior y sus efectos en el desarrollo académico de la persona sorda. En $I V$ Encuentro Nacional de Sordos Universitarios. Pasto: Universidad de Nariño.

Tovar, L. A. (2010). La creación de neologismos en la lengua de señas colombiana. Lenguaje, 38(2), 277-312.

Vernon, M. (2005). Fifty Years of Research on the Intelligence of Deaf and Hard-of-Hearing Children: A Review of Literature and Discussion of Implications. Journal of Deaf Studies and Deaf Education, 10(3), 225-231. 